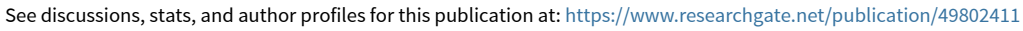

\title{
Two 1,4-dihydropyridine derivatives with potential calcium-channel antagonist activity
}

Article in Acta Crystallographica Section C Crystal Structure Communications · February 2011

Dol: 10.1107/50108270111003362 · Source: PubMed

CITATIONS

4 authors:

Anthony Linden

University of Zurich

1,070 PUBLICATIONS 11,476 CITATIONS

SEE PROFILE

Rahime Simsek

Hacettepe University

95 PUBLICATIONS 651 CITATIONS

SEE PROFILE
Cihat Safak

Hacettepe University

121 PUBLICATIONS 865 CITATIONS

SEE PROFILE

(A) Miyase Gözde Gündüz

Hacettepe University

40 PUBLICATIONS 241 CITATIONS

SEE PROFILE

Some of the authors of this publication are also working on these related projects:

Synthesis, crystal structures and optical properties of mercury(II) halide compounds with (E)-N-(pyridin-2-ylmethylidene)arylamines: Effect of ligand R-group upon structure View project

PhD Thesis View project 


\title{
Communications
}

ISSN 0108-2701

Editor: Anthony Linden

\section{Two 1,4-dihydropyridine derivatives with potential calcium-channel antagonist activity}

\author{
Anthony Linden, Cihat Şafak, Rahime Şimşek and Miyase G. Gündüz
}

Acta Cryst. (2011). C67, o80-084

Copyright (C) International Union of Crystallography

Author(s) of this paper may load this reprint on their own web site or institutional repository provided that this cover page is retained. Republication of this article or its storage in electronic databases other than as specified above is not permitted without prior permission in writing from the IUCr.

For further information see http://journals.iucr.org/services/authorrights.html

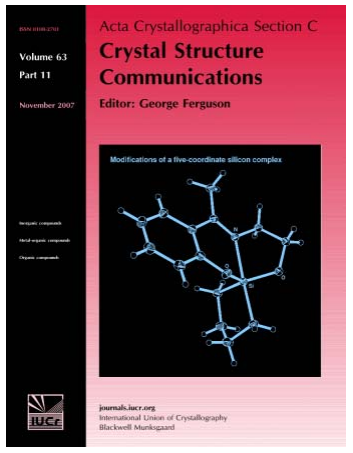

Acta Crystallographica Section C: Crystal Structure Communications specializes in the rapid dissemination of high-quality studies of crystal and molecular structures of interest in fields such as chemistry, biochemistry, mineralogy, pharmacology, physics and materials science. The numerical and text descriptions of each structure are submitted to the journal electronically as a Crystallographic Information File (CIF) and are checked and typeset automatically prior to peer review. The journal is well known for its high standards of structural reliability and presentation. Section $C$ publishes approximately 1000 structures per year; readers have access to an archive that includes high-quality structural data for over 10000 compounds.

Crystallography Journals Online is available from journals.iucr.org 
Acta Crystallographica Section C

Crystal Structure

Communications

ISSN 0108-2701

\section{Two 1,4-dihydropyridine derivatives with potential calcium-channel antagonist activity}

\author{
Anthony Linden, ${ }^{\mathrm{a} *}$ Cihat Șafak, ${ }^{\mathrm{b}}$ Rahime Șimșek $^{\mathrm{b}}$ and \\ Miyase G. Gündüz ${ }^{\mathbf{b}}$
}

anstitute of Organic Chemistry, University of Zürich, Winterthurerstrasse 190, $\mathrm{CH}-8057$ Zürich, Switzerland, and ${ }^{\mathbf{b}}$ Department of Pharmaceutical Chemistry, Faculty of Pharmacy, Hacettepe University, 06100 Ankara, Turkey Correspondence e-mail: alinden@oci.uzh.ch

Received 25 January 2011

Accepted 25 January 2011

Online 27 January 2011

The title compounds, benzyl 4-(3-chloro-2-fluorophenyl)2-methyl-5-oxo-4,5,6,7-tetrahydro- $1 H$-cyclopenta[ $b]$ pyridine3-carboxylate, $\mathrm{C}_{23} \mathrm{H}_{19} \mathrm{ClFNO}_{3}$, (I), and 3-pyridylmethyl 4-[2-fluoro-3-(trifluoromethyl)phenyl]-2,6,6-trimethyl-5-oxo1,4,5,6,7,8-hexahydroquinoline-3-carboxylate, $\mathrm{C}_{26} \mathrm{H}_{24} \mathrm{~F}_{4} \mathrm{~N}_{2} \mathrm{O}_{3}$, (II), belong to a class of 1,4-dihydropyridines whose members sometimes display calcium modulatory properties. The 1,4dihydropyridine ring in each structure has a shallower than usual shallow-boat conformation and is nearly planar in (I). In each structure, the halogen-substituted benzene ring is oriented such that the halogen substituents are in a synperiplanar orientation with respect to the 1,4-dihydropyridine ring plane. The oxocyclopentene ring in (I) is planar, while the oxocyclohexene ring in (II) has a half-chair conformation, which is less commonly observed than the envelope conformation usually found in related compounds. In (I), the frequently observed intermolecular $\mathrm{N}-\mathrm{H} \cdots \mathrm{O}$ hydrogen bond between the amine group and the carbonyl $\mathrm{O}$ atom of the oxocyclopentene ring of a neighbouring molecule links the molecules into extended chains; there are no other significant intermolecular interactions. By contrast, the amine group in (II) forms an $\mathrm{N}-\mathrm{H} \cdots \mathrm{N}$ hydrogen bond with the pyridine ring $\mathrm{N}$ atom of a neighbouring molecule. Additional $\mathrm{C}-\mathrm{H} \cdots \mathrm{O}$ interactions complete a two-dimensional hydrogen-bonded network. The halogen-substituted benzene ring has a weak intramolecular $\pi-\pi$ interaction with the pyridine ring. A stronger $\pi-\pi$ interaction occurs between the $1,4-\mathrm{di}$ hydropyridine rings of centrosymmetrically related molecules.

\section{Comment}

Cardiovascular diseases include disorders of the heart and blood vessels, hypertension, peripheral artery disease, rheumatic heart disease, congenital heart disease and heart failure. Calcium-channel antagonists inhibit muscle contraction by blocking the influx of $\mathrm{Ca}^{2+}$ through calcium channels and are used as anti-anginal and antihypertensive drugs (Triggle \& Swamy, 1980; Janis \& Triggle, 1984). 1,4-Dihydropyridine (1,4DHP) derivatives are the most studied group and nifedipine is the prototype of calcium-channel antagonists (Triggle, 1990, 2003; Şafak \& Şimşek, 2006; Bülbül et al., 2009). Modifications to the nifedipine structure, such as replacing the ester moiety with various acyl analogues or fusing one of the carbonyl groups into the ring system, produces some active molecules (Şimşek et al., 2006; Gündüz et al., 2009). Following on from these structure-activity relationship studies and our experience in this area, we synthesized benzyl 4-(3-chloro-2-fluorophenyl)-2-methyl-5-oxo-4,5,6,7-tetrahydro- $1 H$-cyclopenta[b]pyridine-3-carboxylate, (I), and 3-pyridylmethyl 4-[2-fluoro-3(trifluoromethyl)phenyl]-2,6,6-trimethyl-5-oxo-1,4,5,6,7,8-hexahydroquinoline-3-carboxylate, (II). Compound (I) shows calcium-channel blocker activity in isolated rat ileum and rat thoracic artery. Compound (II) also demonstrates calciumchannel blocker activity. The maximum relaxant responses $\left(E_{\max }\right)$ and $\mathrm{p} D_{2}$ values of (II) were determined on isolated strips of rabbit gastric fundus smooth muscle (Şafak, 2010).

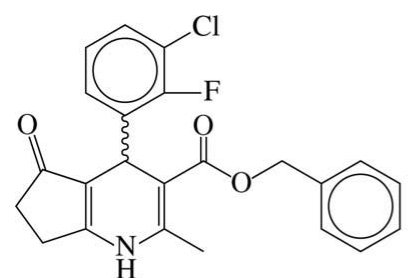

(I)

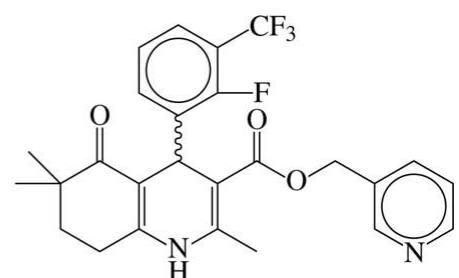

(II)
Views of the asymmetric units of the structures of (I) and (II) are shown in Figs. 1 and 2, respectively. Most of the bond lengths and angles in (I) and (II) have normal values. There are small angular distortions about atom $\mathrm{C} 2$ and the ester $\mathrm{C}$ atom [C9 in (I) and C10 in (II)] (Tables 1 and 3), which result from steric interactions between the methyl substituent at $\mathrm{C} 2$ and atom $\mathrm{O} 1$ of the ester substituent at $\mathrm{C} 3[\mathrm{O} 1 \cdots \mathrm{C} 8$ in (I) and O1..C9 in (II) are both 2.847 (2) $\AA$ ]. The presence of $\pi$-electron conjugation keeps the ester group at $\mathrm{C} 3$ almost coplanar with the endocyclic double bond $[\mathrm{C} 2=\mathrm{C} 3-$ $\mathrm{C} 9=\mathrm{O} 1=-11.3(3)^{\circ}$ for $(\mathrm{I})$ and $\mathrm{C} 2=\mathrm{C} 3-\mathrm{C} 10=\mathrm{O} 1=$ $-5.6(3)^{\circ}$ for (II)] and prevents the ester group from rotating into a sterically more amenable orientation. These properties are consistent with those of related compounds (Linden et al., 2005, 2006).

The 1,4-DHP rings in (I) and (II) have very shallow boat conformations. In (I), the ring is almost completely planar, with atoms N1 and C4 lying just 0.0342 (18) and 0.0612 (19) ̊, respectively, from the plane defined by atoms $\mathrm{C} 2 / \mathrm{C} 3 / \mathrm{C} 4 \mathrm{a} / \mathrm{C} 7 \mathrm{a}$. The corresponding displacements in (II) are 0.0296 (14) and 0.1004 (16) $\AA$, respectively [atom C8a is in the position represented by $\mathrm{C7a}$ in (I)]. The conformations of 4-aryl-1,4DHP rings have been discussed previously (Goldmann \& Stoltefuss, 1991; Linden et al., 1998, 2002, 2005; Şimşek et al., 2000) and it is usual for the ring to have a shallow-boat conformation, although considerable variation in the shal- 


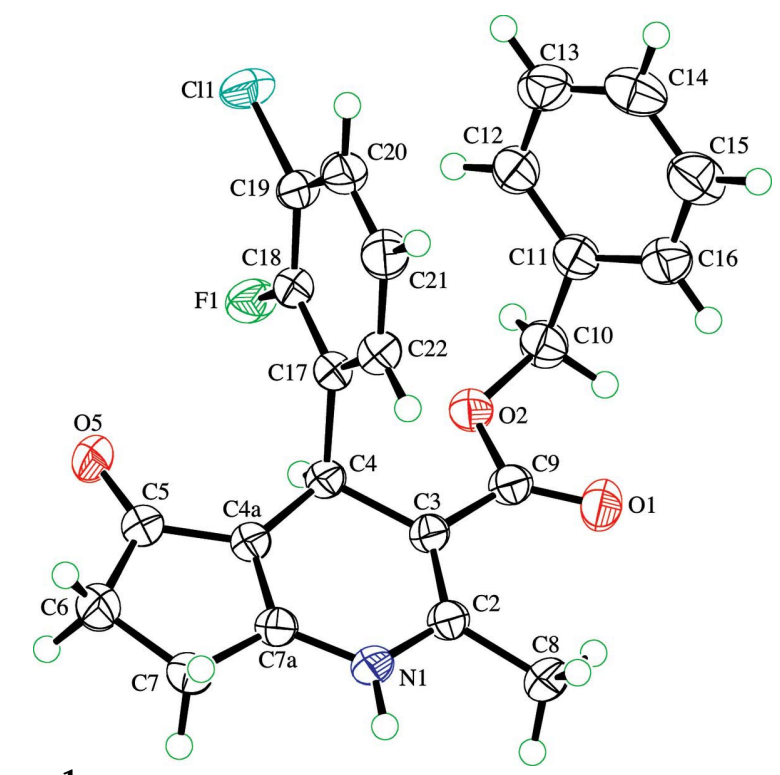

Figure 1

A view of the molecule of (I), showing the atom-labelling scheme. Displacement ellipsoids are drawn at the $50 \%$ probability level.

lowness of the boat is evident. The displacement of atom $\mathrm{C} 4$ from the base of the boat in 1,4-DHP rings is frequently found to be around $0.30 \AA$ (Şimşek et al., 2000). The deviations shown by atom N1 are generally smaller and spread fairly evenly over the range $0.00-0.19 \AA$ (Şimşek et al., 2000; Linden et al., 2002). The deviations shown by atoms N1 in (I) and (II) fall well within this range, while those of $\mathrm{C} 4$ show that the $\mathrm{C} 4$ end of the boat is much flatter than normal. A completely planar 1,4-DHP ring was found in the structure of $N, N$-diethyl2,6,6-trimethyl-4-(3-nitrophenyl)-5-oxo-1,4,5,6,7,8-hexahydroquinoline-3-carboxamide (Linden et al., 2002).

Another measure of the planarity of 1,4-DHP rings is the sum of the magnitudes of the six intraring torsion angles, $P$, around the ring (Fossheim et al., 1988). For (I) and (II), the values of $P$ are $20.0(7)$ and $25.2(7)^{\circ}$, respectively, which demonstrates that the boat conformations are indeed quite shallow. A mean value of $77(2)^{\circ}$ was found previously for 1,4DHP rings (Linden et al., 2002), although the $P$ values generally vary over a wide range from 4 to $130^{\circ}$. For nifedipine itself, $P$ is $72^{\circ}$ (Miyamae et al., 1986).

The planes of the 3-chloro-2-fluorophenyl ring in (I) and the 2-fluoro-3-(trifluoromethyl)phenyl ring in (II) lie in the usual synperiplanar orientation, which places the benzene-ring substituents above the $\mathrm{C} 4-\mathrm{H}$ bond rather than over the 1,4DHP ring, which, because of the substituent in the 2-position of the phenyl ring, would be sterically unfavourable. The $\mathrm{N} 1 \cdots \mathrm{C} 4-\mathrm{C} 17-\mathrm{C} 22$ torsion angles are 10.9 (2) and $5.8(2)^{\circ}$ for (I) and (II), respectively. The corresponding torsion angles in related structures are clustered around $0^{\circ}$ and rarely exceed $\pm 30^{\circ}$ (Linden et al., 2002). The observed orientation of the halophenyl ring brings the $\mathrm{C} 22-\mathrm{H} 22$ bond over the centre of the 1,4-DHP ring, and the distance from atom $\mathrm{H} 22$ to the centroid of the 1,4-DHP ring is just $2.81 \AA$ in (I) and $2.67 \AA$ in (II). The shorter distance for the latter is a consequence of the slightly deeper boat conformation of the 1,4-DHP ring, which

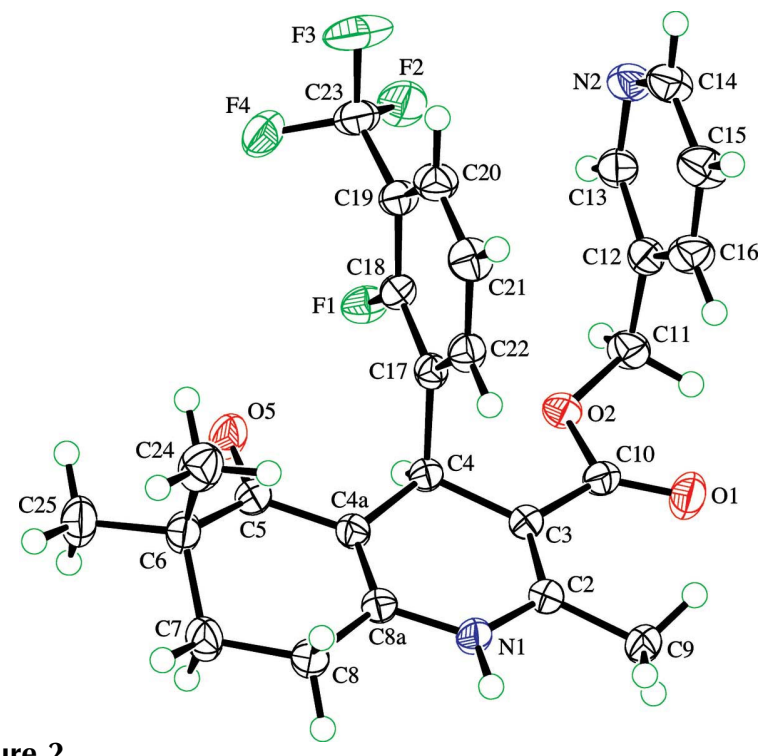

Figure 2

A view of the molecule of (II), showing the atom-labelling scheme. Displacement ellipsoids are drawn at the $50 \%$ probability level.

raises the halophenyl ring up higher and thereby points the $\mathrm{C} 22-\mathrm{H} 22$ bond more deeply into the centre of the 1,4-DHP ring.

The oxocyclopentene ring in (I) is almost planar, with a maximum deviation from the mean plane defined by the five ring atoms of 0.0292 (19) $\AA$ for atom C7a. The angle between the plane defined by the base of the 1,4-DHP ring boat (atoms $\mathrm{C} 2 / \mathrm{C} 3 / \mathrm{C} 4 \mathrm{a} / \mathrm{C} 7 \mathrm{a}$ ) and that of the oxocyclopentene ring is $5.05(12)^{\circ}$, which indicates that the fused rings are essentially coplanar. The oxocyclohexene ring in (II) adopts a nearly ideal half-chair conformation twisted on the $\mathrm{C} 6-\mathrm{C} 7$ bond, with atoms C6 and C7 lying 0.289 (2) and 0.382 (2) A, respectively, from the plane defined by the remaining four ring atoms, viz. C4a/C5/C8/C8a. The ring-puckering parameters (Cremer \& Pople, 1975) for this ring are $Q=0.4370$ (19) $\AA, \theta=$ $130.1(2)^{\circ}$ and $\varphi_{2}=335.1(3)^{\circ}$ for the atom sequence C4a-C5C6-C7-C8-C8a. The ideal values for a half-chair conformation in a six-membered ring are $\theta=50^{\circ}\left(\right.$ or $\left.180-50=130^{\circ}\right)$ and $\varphi_{2}=(n \times 60)+30^{\circ}$, where $n$ is an integer. Atom C7 of the ring flips down on the opposite side of the oxocyclohexene ring plane to the 2-fluoro-3-(trifluoromethyl)phenyl ring substituent of the adjacent 1,4-DHP ring. A half-chair conformation was also observed in the structure of methyl 4-(2,4-chlorophenyl)-2-methyl-7-phenyl-5-oxo-1,4,5,6,7,8hexahydroquinoline-3-carboxylate monohydrate (Linden et al., 2006). More frequently, the oxocyclohexene ring in similar structures involving the 5-oxoquinoline or 1,8-dioxoacridine fragment adopts an envelope conformation, with atom C7 always being the out-of-plane atom, and the side of the oxocyclohexene ring to which $\mathrm{C} 7$ deviates is, in the majority, but not all, of these structures, opposite to that in (I) (Linden et al., 2002, 2005).

The angle between the plane of the 3-chloro-2-fluorophenyl ring and that of the phenyl ring of the ester substituent in (I) is $32.65(10)^{\circ}$, which precludes any chance of there being a $\pi-\pi$ 


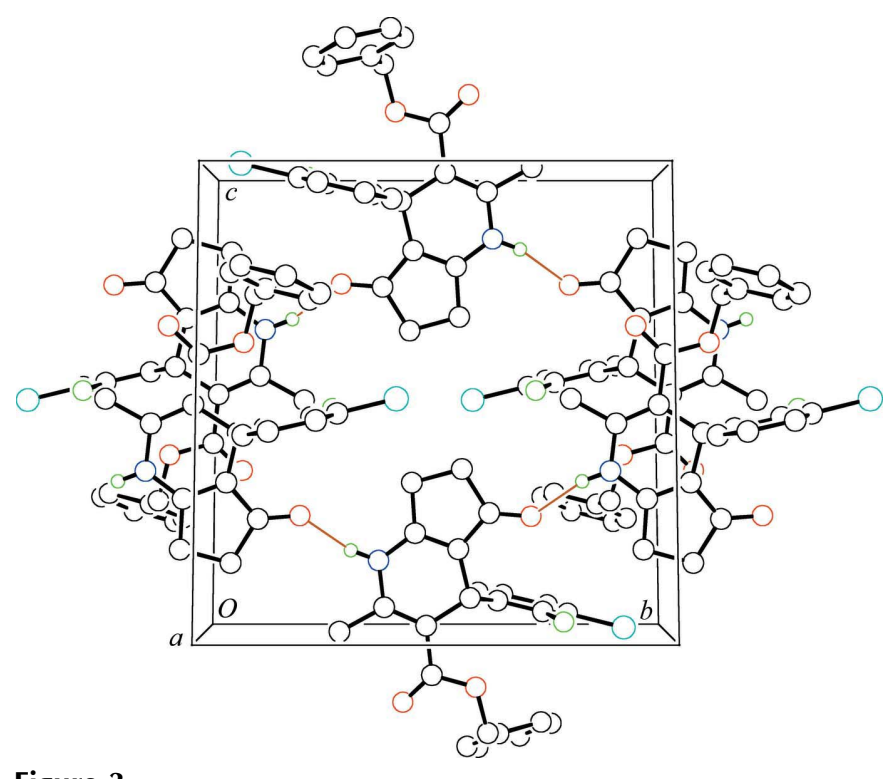

Figure 3

A view, down the $a$ axis, of the crystal packing in (I), showing the chains of molecules formed by the $\mathrm{N}-\mathrm{H}$. . O hydrogen bonds (thin lines). Most $\mathrm{H}$ atoms have been omitted for clarity.

interaction between these rings. There are also no other $\pi-\pi$ interactions evident in the structure. In contrast, a weak intramolecular $\pi-\pi$ interaction may be present between the 2-fluoro-3-(trifluoromethyl)phenyl ring and the pyridine ring in (II). The angle between the planes of these rings is $2.94(8)^{\circ}$. The distance between the ring centroids is quite long at 4.0014 (10) $\AA$, although the perpendicular distance from the pyridine ring centroid to the plane of the other ring is 3.8258 (7) $\AA$. The angle between these two vectors is $17.0^{\circ}$, which indicates a significant degree of offset of the two parallel rings. A stronger $\pi-\pi$ interaction in (II) appears to exist between the 1,4-DHP rings of adjacent molecules related by a centre of inversion. The distance between the ring centroids of the molecules at $(x, y, z)$ and $(-x+2,-y,-z+2)$ is 3.7634 (9) $\AA$, while the perpendicular distance from the centroid of one ring to the plane of the other is 3.6037 (6) $\AA$. The angle between these two vectors is $16.8^{\circ}$ and the slippage of the centroids is $1.09 \AA$.

In compound (I), an intermolecular $\mathrm{N}-\mathrm{H} \cdots \mathrm{O}$ hydrogen bond between the amine group and the carbonyl $\mathrm{O}$ atom of the oxocyclopentene ring of a neighbouring molecule (Table 2 and Fig. 3) links the molecules into extended chains which run parallel to the [010] direction and can be described by a graphset motif of $C(6)$ (Bernstein et al., 1995). The same $C(6)$ motif has been observed in the crystal structures of several other closely related 1,4-DHP compounds (Linden et al., 1998, 2002, 2004, 2005, 2006; Şimşek et al., 2000). There are no significant inter- or intramolecular $\mathrm{C}-\mathrm{H} \cdots X(X=\mathrm{O}, \mathrm{N}$ or halogen $)$ interactions in the structure.

A more unusual hydrogen bond is present in the structure of (II). This time, the amine group forms an intermolecular $\mathrm{N}-\mathrm{H} \cdots \mathrm{N}$ hydrogen bond with the pyridine ring $\mathrm{N}$ atom of a neighbouring molecule (Table 4 and Fig. 4). This interaction links the molecules into extended chains which run parallel to

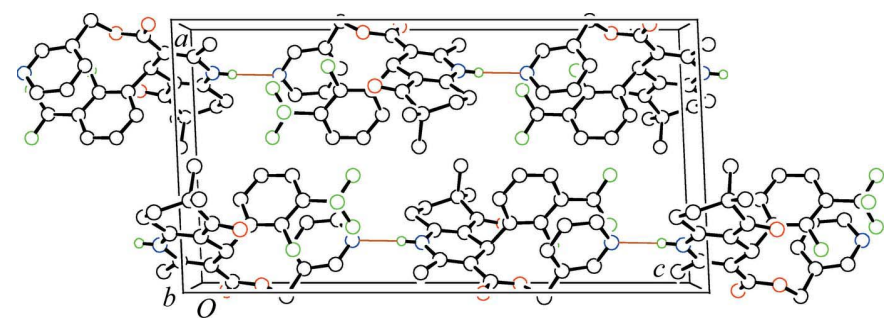

Figure 4

A view, down the $b$ axis, of the crystal packing in (II), showing the chains of molecules formed by the $\mathrm{N}-\mathrm{H} \cdots \mathrm{N}$ hydrogen bonds (thin lines). The sheets formed by the additional $\mathrm{C}-\mathrm{H} \cdots \mathrm{O}$ interactions lie parallel to the (100) plane. Most $\mathrm{H}$ atoms have been omitted for clarity.

the [001] direction and can be described by a graph-set motif of $C(10)$. Atom $\mathrm{O} 5$ of the oxocyclohexene ring now acts as an acceptor of a weak $\mathrm{C}-\mathrm{H} \cdots \mathrm{O}$ interaction from atom $\mathrm{C} 15-\mathrm{H}$ of a neighbouring molecule. This interaction links the molecules into extended chains which run parallel to the [010] direction and can be described by a graph-set motif of $C(12)$. A further $\mathrm{C}-\mathrm{H} \cdots \mathrm{O}$ interaction between $\mathrm{C} 7-\mathrm{H}$ and ester atom $\mathrm{O} 1$ of another neighbouring molecule forms a centrosymmeteric $R_{2}^{2}(18)$ ring. The combination of all the hydrogenbonding interactions in (II) leads to sheets of molecules which lie parallel to the (100) plane.

\section{Experimental}

Compounds (I) and (II) were prepared according to the method described by Şimşek et al. (2008) by refluxing the appropriate dicarbonyl compound, 2,3-disubstituted benzaldehyde, acetoacetate derivative and ammonium acetate in methanol for $8 \mathrm{~h}$. After cooling, compound (I) was poured into ice-water. The obtained precipitate was crystallized from ethyl acetate to give diffraction quality crystals (yield 35\%, m.p. $445 \mathrm{~K}$ ). Analysis calculated for $\mathrm{C}_{23} \mathrm{H}_{19} \mathrm{ClFNO}_{3}$ : C $67.07, \mathrm{H}$ 4.65, N 3.40\%; found: C 66.67, H 4.67, N 3.40\%. Compound (II) was obtained in a crystalline state suitable for crystallographic analysis after cooling the reaction mixture (yield $79 \%$, m.p. $462 \mathrm{~K}$ ). Analysis calculated for $\mathrm{C}_{26} \mathrm{H}_{24} \mathrm{~F}_{4} \mathrm{~N}_{2} \mathrm{O}_{3}$ : C 63.93, H 4.95, N 5.73\%; found: C $63.76, \mathrm{H} 4.86, \mathrm{~N} 5.86 \%$. The structures of the compounds were elucidated by IR, ${ }^{1} \mathrm{H}$ NMR, ${ }^{13} \mathrm{C}$ NMR and mass spectroscopy; the spectroscopic details are available in the archived CIF.

\section{Compound (I)}

Crystal data
$\mathrm{C}_{23} \mathrm{H}_{19} \mathrm{ClFNO}_{3}$
$M_{r}=411.86$
Monoclinic, $P 2_{1} / c$
$a=10.7944(2) \AA$
$b=13.5205(3) \AA$
$c=14.0573(3) \AA$
$\beta=104.2378(13)^{\circ}$

$V=1988.58(7) \AA^{3}$

$Z=4$

Mo $K \alpha$ radiation

$\mu=0.23 \mathrm{~mm}^{-1}$

$T=160 \mathrm{~K}$

$0.30 \times 0.28 \times 0.15 \mathrm{~mm}$

\section{Data collection}

Nonius KappaCCD area-detector diffractometer

Absorption correction: multi-scan (Blessing, 1995)

$T_{\text {min }}=0.914, T_{\max }=0.974$
49390 measured reflections 4536 independent reflections $R_{\text {int }}=0.076$ 3193 reflections with $I>2 \sigma(I)$ 
Table 1

Selected geometric parameters $\left(\AA{ }^{\circ},{ }^{\circ}\right.$ for (I).

\begin{tabular}{llll}
\hline $\mathrm{O} 1-\mathrm{C} 9$ & $1.214(2)$ & $\mathrm{C} 3-\mathrm{C} 9$ & $1.480(3)$ \\
$\mathrm{O} 2-\mathrm{C} 9$ & $1.350(2)$ & $\mathrm{C} 3-\mathrm{C} 4$ & $1.533(2)$ \\
$\mathrm{N} 1-\mathrm{C} 7 \mathrm{a}$ & $1.353(2)$ & $\mathrm{C} 4-\mathrm{C} 4 \mathrm{a}$ & $1.503(3)$ \\
$\mathrm{N} 1-\mathrm{C} 2$ & $1.395(2)$ & $\mathrm{C} 4 \mathrm{a}-\mathrm{C} 7 \mathrm{a}$ & $1.354(2)$ \\
$\mathrm{C} 2-\mathrm{C} 3$ & $1.353(2)$ & & \\
$\mathrm{C} 2-\mathrm{N} 1-\mathrm{C} 7 \mathrm{a}$ & $120.52(16)$ & $\mathrm{C} 3-\mathrm{C} 4-\mathrm{C} 4 \mathrm{a}$ & $109.00(14)$ \\
$\mathrm{N} 1-\mathrm{C} 2-\mathrm{C} 3$ & $120.74(17)$ & $\mathrm{C} 4-\mathrm{C} 4 \mathrm{a}-\mathrm{C} 7 \mathrm{a}$ & $123.67(16)$ \\
$\mathrm{N} 1-\mathrm{C} 2-\mathrm{C} 8$ & $111.90(16)$ & $\mathrm{N} 1-\mathrm{C} 7 \mathrm{a}-\mathrm{C} 4 \mathrm{a}$ & $122.29(17)$ \\
$\mathrm{C} 3-\mathrm{C} 2-\mathrm{C} 8$ & $127.37(17)$ & $\mathrm{O} 1-\mathrm{C} 9-\mathrm{O} 2$ & $122.37(17)$ \\
$\mathrm{C} 2-\mathrm{C} 3-\mathrm{C} 4$ & $123.47(17)$ & $\mathrm{O} 1-\mathrm{C} 9-\mathrm{C} 3$ & $127.26(17)$ \\
$\mathrm{C} 2-\mathrm{C} 3-\mathrm{C} 9$ & $120.55(16)$ & $\mathrm{O} 2-\mathrm{C} 9-\mathrm{C} 3$ & $110.36(15)$ \\
& & &
\end{tabular}

Table 2

Hydrogen-bond geometry $\left(\AA,^{\circ}\right)$ for (I).

\begin{tabular}{lllll}
\hline$D-\mathrm{H} \cdots A$ & $D-\mathrm{H}$ & $\mathrm{H} \cdots A$ & $D \cdots A$ & $D-\mathrm{H} \cdots A$ \\
\hline $\mathrm{N} 1-\mathrm{H} 1 \cdots \mathrm{O}^{\mathrm{i}}$ & $0.88(2)$ & $1.92(2)$ & $2.772(2)$ & $163(2)$ \\
\hline
\end{tabular}

Symmetry code: (i) $-x+1, y+\frac{1}{2},-z+\frac{3}{2}$.

\section{Refinement}

$R\left[F^{2}>2 \sigma\left(F^{2}\right)\right]=0.048$

$w R\left(F^{2}\right)=0.130$

$S=1.03$

4536 reflections

268 parameters

$\mathrm{H}$ atoms treated by a mixture of independent and constrained refinement

$\Delta \rho_{\max }=0.31{\mathrm{e} \AA^{-3}}^{-3}$

$\Delta \rho_{\min }=-0.22 \mathrm{e}^{-3}$

\section{Compound (II)}

Crystal data

$\mathrm{C}_{26} \mathrm{H}_{24} \mathrm{~F}_{4} \mathrm{~N}_{2} \mathrm{O}_{3}$
$M_{r}=488.48$
Monoclinic, $P 2_{1} / c$
$a=11.3696(2) \AA$
$b=9.2177(2) \AA$
$c=21.9577(3) \AA$
$\beta=92.5683(11)^{\circ}$

$V=2298.89(7) \AA^{3}$

$Z=4$

Mo $K \alpha$ radiation

$\mu=0.11 \mathrm{~mm}^{-1}$

$T=160 \mathrm{~K}$

$0.25 \times 0.25 \times 0.25 \mathrm{~mm}$

\section{Data collection}

Nonius KappaCCD area-detector diffractometer

49934 measured reflections

5242 independent reflections 3791 reflections with $I>2 \sigma(I)$ $R_{\text {int }}=0.056$

\section{Refinement \\ $R\left[F^{2}>2 \sigma\left(F^{2}\right)\right]=0.049$ \\ $w R\left(F^{2}\right)=0.133$ \\ $S=1.03$ \\ 5242 reflections \\ 324 parameters}

$$
\begin{aligned}
& \mathrm{H} \text { atoms treated by a mixture of } \\
& \text { independent and constrained } \\
& \text { refinement } \\
& \Delta \rho_{\max }=0.29 \mathrm{e}^{-3} \\
& \Delta \rho_{\min }=-0.27 \mathrm{e}^{-3}
\end{aligned}
$$

The amine $\mathrm{H}$ atoms were placed in the positions indicated by difference electron-density maps and their positions were allowed to refine together with individual isotropic displacement parameters. The methyl $\mathrm{H}$ atoms were constrained to an ideal geometry, with $\mathrm{C}-\mathrm{H}=0.98 \AA$ and $U_{\text {iso }}(\mathrm{H})=1.5 U_{\text {eq }}(\mathrm{C})$, but were allowed to rotate freely about their adjacent $\mathrm{C}-\mathrm{C}$ bonds. All other $\mathrm{H}$ atoms were placed in geometrically idealized positions and constrained to ride on their parent atoms, with $\mathrm{C}-\mathrm{H}=0.95$ (aromatic), 0.99 (methylene) or $1.00 \AA$ (methine) and with $U_{\text {iso }}(\mathrm{H})=1.2 U_{\text {eq }}(\mathrm{C})$.
Table 3

Selected geometric parameters $\left(\AA,^{\circ}\right)$ for (II).

\begin{tabular}{llll}
\hline $\mathrm{O} 1-\mathrm{C} 10$ & $1.209(2)$ & $\mathrm{C} 3-\mathrm{C} 10$ & $1.466(2)$ \\
$\mathrm{O} 2-\mathrm{C} 10$ & $1.360(2)$ & $\mathrm{C} 3-\mathrm{C} 4$ & $1.527(2)$ \\
$\mathrm{N} 1-\mathrm{C} 8 \mathrm{a}$ & $1.373(2)$ & $\mathrm{C} 4-\mathrm{C} 4 \mathrm{a}$ & $1.517(2)$ \\
$\mathrm{N} 1-\mathrm{C} 2$ & $1.385(2)$ & $\mathrm{C} 4 \mathrm{a}-\mathrm{C} 8 \mathrm{a}$ & $1.353(2)$ \\
$\mathrm{C} 2-\mathrm{C} 3$ & $1.353(2)$ & & \\
$\mathrm{C} 2-\mathrm{N} 1-\mathrm{C} 8 \mathrm{a}$ & $122.48(14)$ & $\mathrm{C} 3-\mathrm{C} 4-\mathrm{C} 4 \mathrm{a}$ & $111.13(12)$ \\
$\mathrm{N} 1-\mathrm{C} 2-\mathrm{C} 3$ & $120.37(15)$ & $\mathrm{C} 4-\mathrm{C} 4 \mathrm{a}-\mathrm{C} 8 \mathrm{a}$ & $122.22(15)$ \\
$\mathrm{N} 1-\mathrm{C} 2-\mathrm{C} 9$ & $112.87(14)$ & $\mathrm{N} 1-\mathrm{C} 8 \mathrm{a}-\mathrm{C} 4 \mathrm{a}$ & $120.97(15)$ \\
$\mathrm{C} 3-\mathrm{C} 2-\mathrm{C} 9$ & $126.76(15)$ & $\mathrm{O} 1-\mathrm{C} 10-\mathrm{O} 2$ & $121.85(15)$ \\
$\mathrm{C} 2-\mathrm{C} 3-\mathrm{C} 4$ & $122.23(14)$ & $\mathrm{O} 2-\mathrm{C} 10-\mathrm{C} 3$ & $110.26(14)$ \\
$\mathrm{C} 2-\mathrm{C} 3-\mathrm{C} 10$ & $121.32(15)$ & $\mathrm{O} 1-\mathrm{C} 10-\mathrm{C} 3$ & $127.89(15)$ \\
\end{tabular}

Table 4

Hydrogen-bond geometry $\left(\AA{ }^{\circ}\right)$ for (II).

\begin{tabular}{lllll}
\hline$D-\mathrm{H} \cdots A$ & $D-\mathrm{H}$ & $\mathrm{H} \cdots A$ & $D \cdots A$ & $D-\mathrm{H} \cdots A$ \\
\hline $\mathrm{N} 1-\mathrm{H} 1 \cdots \mathrm{N} 2^{\mathrm{i}}$ & $0.90(2)$ & $2.11(2)$ & $3.0073(19)$ & $169.5(19)$ \\
$\mathrm{C} 7-\mathrm{H} 72 \cdots 1^{\mathrm{ii}}$ & 0.99 & 2.54 & $3.427(3)$ & 149 \\
$\mathrm{C} 15-\mathrm{H} 15 \cdots \mathrm{O} 5^{\mathrm{iii}}$ & 0.95 & 2.58 & $3.172(2)$ & 120 \\
\hline
\end{tabular}

Symmetry codes: (i) $x,-y+\frac{1}{2}, z+\frac{1}{2}$; (ii) $-x+2,-y,-z+2$; (iii) $x, y+1, z$.

For both compounds, data collection: COLLECT (Nonius, 2000); cell refinement: DENZO-SMN (Otwinowski \& Minor, 1997); data reduction: DENZO-SMN and SCALEPACK (Otwinowski \& Minor, 1997); program(s) used to solve structure: SIR92 (Altomare et al., 1994); program(s) used to refine structure: SHELXL97 (Sheldrick, 2008); molecular graphics: ORTEPII (Johnson, 1976); software used to prepare material for publication: SHELXL97 and PLATON (Spek, 2009).

Supplementary data for this paper are available from the IUCr electronic archives (Reference: SK3400). Services for accessing these data are described at the back of the journal.

\section{References}

Altomare, A., Cascarano, G., Giacovazzo, C., Guagliardi, A., Burla, M. C. Polidori, G. \& Camalli, M. (1994). J. Appl. Cryst. 27, 435.

Bernstein, J., Davis, R. E., Shimoni, L. \& Chang, N.-L. (1995). Angew. Chem. Int. Ed. 34, 1555-1573.

Blessing, R. H. (1995). Acta Cryst. A51, 33-38.

Bülbül, B., Öztürk, G. S., Vural, M., Şimşek, R., Sarioğlu, Y., Linden, A., Ülgen, M. \& Şafak, C. (2009). Eur. J. Med. Chem. 44, 2052-2058.

Cremer, D. \& Pople, J. A. (1975). J. Am. Chem. Soc. 97, 1354-1358.

Fossheim, R., Joslyn, A., Solo, A. J., Luchowski, E., Rutledge, A. \& Triggle, D. J. (1988). J. Med. Chem. 31, 300-305.

Goldmann, S. \& Stoltefuss, J. (1991). Angew. Chem. Int. Ed. Engl. 30, 15591578.

Gündüz, M. G., Celebi, S., Kaygisiz, B., Şimşek, R., Erol, K. \& Şafak, C. (2009). Lat. Am. J. Pharm. 28, 922-926.

Janis, R. A. \& Triggle, D. J. (1984). Drug Dev. Res. 4, 257-274.

Johnson, C. K. (1976). ORTEPII. Report ORNL-5138. Oak Ridge National Laboratory, Tennessee, USA.

Linden, A., Gündüz, M. G., Şimşek, R. \& Şafak, C. (2006). Acta Cryst. C62, o227-o230.

Linden, A., Şafak, C. \& Aydın, F. (2004). Acta Cryst. C60, o711-o713.

Linden, A., Şafak, C. \& Kismetlı, E. (2002). Acta Cryst. C58, o436-0438.

Linden, A., Şafak, C. \& Şimşek, R. (1998). Acta Cryst. C54, 879-882.

Linden, A., Şimşek, R., Gündüz, M. \& Şafak, C. (2005). Acta Cryst. C61, o731o734.

Miyamae, A., Koda, S. \& Morimoto, Y. (1986). Chem. Pharm. Bull. 34, 30713074.

Nonius (2000). COLLECT. Nonius BV, Delft, The Netherlands. 


\section{organic compounds}

Otwinowski, Z. \& Minor, W. (1997). Methods in Enzymology, Vol. 276, Macromolecular Crystallography, Part A, edited by C. W. Carter Jr \& R. M. Sweet, pp. 307-326. New York: Academic Press.

Safak, C. (2010). Private communication.

Şafak, C. \& Şimşek, R. (2006). Mini Rev. Med. Chem. 6, 747-755.

Sheldrick, G. M. (2008). Acta Cryst. A64, 112-122.

Şimşek, R., Gündüz, M. G., Sırmagül, B., Şafak, C., Erol, K. \& Linden, A. (2006). Arzneim. Forsch./Drug Res. 56, 529-534.
Şimşek, R., Linden, A. \& Şafak, C. (2000). Acta Cryst. C56, 351-353.

Şimşek, R., Öztürk, G. S., Vural, İ. M., Gündüz, M. G., Sarioğlu, Y. \& Şafak, C. (2008). Arch. Pharm. Chem. Life Sci. 341, 55-60.

Spek, A. L. (2009). Acta Cryst. D65, 148-155.

Triggle, D. J. (1990). Drug Discovery Technologies, edited by C. R. Clark \& H. Moos, pp. 167-195. Chichester: John Wiley \& Sons.

Triggle, D. J. (2003). Mini Rev. Med. Chem. 3, 215-223.

Triggle, D. J. \& Swamy, V. C. (1980). Chest, 78, 174-179. 